\title{
Health-Related Quality of Life among Elderly Population of Bangladesh
}

\author{
Ahmmed FMS1, Rahman MS', Zafreen F3, Ara R' ${ }^{4}$, Islam MZ ${ }^{5}$
}

DOI: https:/ / doi.org/ 10.3329/ jafmc.v15i2.50828

\begin{abstract}
Introduction: Elderly population in Bangladesh is one of the largest in the world in term of absolute number and ageing is an emerging problem. Elderly are at risk from non-communicable diseases as well as mental problems and health-related quality of life (HRQoL) affects in urban and rural elderly.
\end{abstract}

Objective: To find out and compare HRQoL in urban and rural elderly population of Bangladesh.

Materials and Methods: A comparative cross-sectional study was carried out to compare HRQoL in urban and rural elderly. This was a two samples study; 130 each from urban and rural. Total 260 elderly were selected conveniently. Data were collected through face to face interview using a pre-tested semi structured questionnaire of SF-36 v2 HRQoL survey. This study was carried in urban elderly residing in Ward number 3, Race Course, Cumilla City Corporation and in rural elderly residing in Noapuskuni Village of Babutipara Union, Muradnager Upazila, Cumilla. This one-year study was conducted from 15 July 2017 to 14 June 2018.

Results: Majority of the elderly were Muslim (91.5\%), female (53.5\%), married (59.6\%) and from joint family (91\%). The mean \pm SD age of elderly was $69.26 \pm 6.337$ years and mean \pm SD monthly family income was Tk. 16561.54 \pm 9192.076 . SF- 36 v2 HRQoL scale; a licensed software-based survey tool was used measure the healthrelated quality of life of elderly. Most of the elderly were found with average physical component summary (PCS) (53.1\%) and mental component summary (MCS) (50.8\%) of HRQoL. Age had significant negative correlation with PCS $(p<0.001)$ and MCS $(p<0.001)$ in urban and rural elderly. Education level of urban and rural elderly had significant positive correlation with PCS $(p<0.01)$ and MCS $(p<0.01)$. Marital status of urban and rural elderly had significant negative correlation with PCS $(p<0.001)$ and MCS $(p<0.001)$ of HRQoL. Among the rural respondents, the mean \pm SD of PCS of male was $43.79 \pm 5.766$ and female was $41.14 \pm 6.860$. The difference was statistically significant $(p<0.05)$. Mean score of PCS of urban and rural respondents were $45.68 \pm 6.366$ and $42.43 \pm 6.467$ respectively. This difference was statistically significant $(p<0.001)$. Mean scores of MCS of urban and rural respondents were $43.96 \pm 4.921$ and $42.56 \pm 7.028$ respectively. This difference was not statistically significant $(\mathrm{p}>0.05)$.

Conclusion: Most of the elderly had average level of health-related quality life. Rural female elderly had significantly lower physical health of HRQOL than that of rural male elderly. Physical dimension of HRQDL of rural elderly was significantly lower than that of urban elderly.

Key-words: Health related quality of life, Physical component, Mental component.

\section{Introduction}

Ageing is an emerging problem in Bangladesh and today, status of older person is going to be a prominent issue. Elderly population in Bangladesh is one of the largest in the world in term of absolute number. In 2017, the average life expectancy is 71.52 years in Bangladesh whereas it was 67.7 years in 2010, 70.4 was in 2013. The number of aged population (60 plus population) is about 5\% (7.3 million), which will reach $8 \%$ (14.6 million) of the total population by year 20251. Elderly in Bangladesh are at risk from non-communicable diseases like cardiovascular diseases, chronic respiratory diseases, renal disease, cancers, and diabetes, as well as musculo-skeletal diseases. In addition, older persons face mental problems linked to declining sources of income, inadequate management of diseases or conditions, loss of loved ones, and loneliness. A lack sustainable support from family, friends and state is likely to deteriorate quality of life of elderly person and cause an individual to perceive old age as uncertain and insecure 2 . HRQoL is an individual's or a group's perceived physical and mental health over time. HRQoL is a multidimensional concept that includes domains related to physical, mental, emotional, and social functioning. It goes beyond direct measures of population health, life expectancy, and causes of death, and focuses on the impact health status has on quality of life. A related concept of HRQoL is well-being, which assesses the positive aspects of a person's life, such as positive emotions and life satisfaction. Focused aspects of HRQoL are the following: Absence of distressing physical symptoms (e.g. pain, dyspnea, nausea, and constipation), Emotional well-being (e.g., happiness, absence of anxiety), functional status (e.g., capacity to do activities of daily living and higher-order functions, such as pleasurable activities), quality of close interpersonal relationships (e.g. with family members, friends), participation in and enjoyment of social activities, satisfaction with medical and financial aspects of treatments, sexuality, body image, and intimacy 3 . Measuring health related quality life of the elderly in Bangladesh can give a clear picture of elderly situation in Bangladesh and outcome of existing health services and social supports.

\section{Materials and Methods}

This comparative cross-sectional study was carried out among 130 each urban and rural elderly residing in ward number 3 , Cumilla Town and Noapuskuni Village of Muradnagar Upazilla respectively during the period of 15 July 2017 to 14 June 2018 to assess and compare their health-related quality of life. Elderly people aged 60 years above who were free from severe physical and mental illness and willing to participate after being informed, were included in this study. Data were collected through face to face interview using a pretested SF-36 v2 survey questionnaire. At the end of the interview each questionnaire was checked, verified on the spot and data were then entered into SF 36 v2 survey tool- a windows-based software to get instant report on

1. Col FM Shamim Ahmmed, MBBS, MPH, MPhil, Assistant Director of Medical Services (ADMS), 11 Infantry Division, Bogura (E-mail afmshamim@gmail.com) 2. Col Md Saydur Rahman, MBBS, MPH, MPhil, Assistant Director of Medical Services, 19 Infantry Division Ghatail 3. Dr Farzana Zafreen, MBBS, MPH, Associate Professor \& Head, Department of Community Medicine, Medical College for Womer \& Hospital, Uttara, Dhaka 4. Dr Rowshan Ara, MBBS, MPH, MPhil, Associate Professor, Department of Population and Dynamics, NIPSOM Dhaka 5. Professor Md Ziaul Islam, MBBS, MPH, PhD, Professor and Head, Department of Community Medicine, NIPSOM, Dhaka. 
the physical and mental dimension of HRQoL of elderly. These data were further analyzed using SPSS version 23.0.

\section{Results}

The mean age of elderly was found $69.26 \pm 6.337$. More than half i.e. $140(53.8 \%)$ elderly were found in the age group of 60-69 years. In urban elderly, male were 58(44.6\%) and female were $72(55.4 \%)$ and in rural elderly male were $63(48.5 \%)$ and female were $67(51.5 \%)$. Regarding marital status of the respondents, $90(69.2 \%)$ were married and 25(19.2\%) were widow in urban elderly, on the other hand, 65(50.0\%) were married and 46(35.4\%) were widows were found among rural elderly. Nearer to the half of the respondent i.e. $116(44.62 \%)$ in urban and $124(47.69 \%)$ in rural were living with joint families. Mean monthly family income of respondents was Taka 16561.54 \pm 9192.08 with Taka 24561.54 \pm 8561.54 in urban and Taka 5895.74 \pm 2427.25 in rural elderly. Regarding level of HRQoL, around than half of the respondents i.e. $74(56.9 \%)$ and $70(53.8 \%)$ in urban and 64(49.2\%) and 62(47.7\%) in rural had "Average" level of physical component summary (PCS) and mental component summary (MCS) of HRQoL respectively (Table-I).

There was a strong and negative correlation between age and PCS in urban $(r=-0.580, p<0.001)$ and moderate and negative correlation in rural $(r=-0.479, p<0.001)$ respondents with statistical significance. There was moderate and negative correlation between age and MCS in urban $(r=-0.448, p<0.001)$ and fair and negative correlation in rural $(r=-0.373, p<0.001)$ respondents with statistical significance. Education level of both urban and rural respondents were found positively correlated with PCS $(r=0.300$, $p<0.05$ and $r=0.339, p<0.05)$ and MCS $(r=407, p<0.05$ and $r=$ $0.250, p<0.05$ ) of HRQoL with statistical significance. Marital status of both urban and rural respondents were found negatively correlated with PCS $(r=-0.420, p<0.05)$ and $r=-0.325, p<0.05)$ and
MCS $(r=-0.359, p<0.05$ and $r=-0.233, p<0.05)$ of HRQoL with statistical significance. Education level of both urban and rural respondents were found positively correlated with PCS $(r=0.300$, $p<0.05$ and $r=0.339, p<0.05)$ and MCS $(r=407, p<0.05$ and $r=$ $0.250, p<0.05)$ of HRQoL with statistical significance. Family type of rural respondents had a moderate and negative correlation with MCS $(r=-0.176, p<0.05)$ with statistically significant. Monthly family income of both urban and rural respondents were found positively correlated with PCS $(r=0.016, p>0.05$ and $r=0.058, p>0.05)$ and MCS ( $r=0.070, p>0.05$ and $r=0.142, p>0.05)$ with no statistical significance (Table-II). PCS of urban and rural respondents were $45.68 \pm 6.366$ and $42.43 \pm 6.467$ respectively. This difference was statistically significant $(p<0.001)$. MCS of urban and rural respondents were $43.96 \pm 4.921$ and $42.56 \pm 7.028$ respectively. This difference was not statistically significant ( $p>0.05)$ (Table-III).

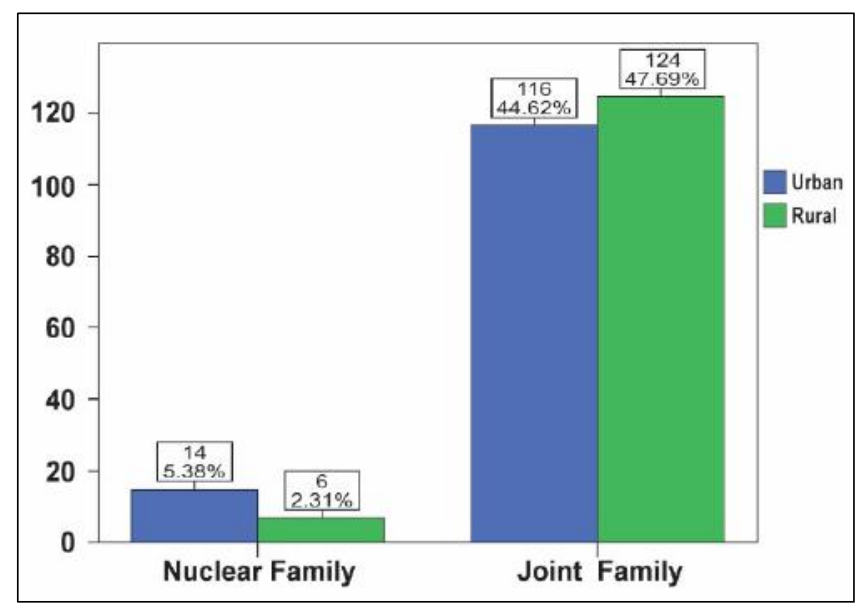

Figure-1: Distribution of urban and rural elderly by family type

Table-I: Age, monthly family income, physical and mental component summery distribution of urban and rural elderly

\begin{tabular}{|c|c|c|c|c|c|}
\hline \multirow{2}{*}{\multicolumn{2}{|c|}{ Characteristics }} & \multicolumn{2}{|c|}{ Residence of elderly } & \multirow{3}{*}{$\begin{array}{c}\begin{array}{c}\text { Total } \\
(n=260)\end{array} \\
140(53.8)\end{array}$} & \multirow{2}{*}{ Statistics } \\
\hline & & \multirow{2}{*}{$\begin{array}{c}\text { Urban }(n=130) \\
74(56.9)\end{array}$} & \multirow{2}{*}{$\begin{array}{c}\text { Rural }(n=130) \\
66(50.8)\end{array}$} & & \\
\hline \multirow{4}{*}{ Age in years } & $60-69$ & & & & \\
\hline & $70-79$ & $41(31.5)$ & $53(40.8)$ & $94(36.2)$ & \\
\hline & $80-90$ & $15(11.5)$ & $11(8.5)$ & $26(10.0)$ & \\
\hline & Mean \pm SD & $69.45 \pm 6.264$ & $69.07 \pm 6.428$ & $69.26 \pm 6.337$ & \\
\hline \multirow{6}{*}{$\begin{array}{l}\text { Monthly family } \\
\text { income } \\
\text { in Taka }\end{array}$} & $\leq 5000$ & $0(0.0)$ & $4(3.1)$ & $4(1.5)$ & \\
\hline & $5001-10000$ & $0(0.0)$ & $107(82.3)$ & $107(41.2)$ & \\
\hline & $10001-15000$ & $3(2.3)$ & $19(4.6)$ & $22(8.5)$ & \\
\hline & $15001-20000$ & $50(38.5)$ & $0(0.0)$ & $50(19.2)$ & \\
\hline & $\geq 20001$ & $77(59.2)$ & $0(0.0)$ & $77(29.6)$ & \\
\hline & Mean \pm SD & $\begin{array}{c}24561.54 \pm \\
8561.54\end{array}$ & $\begin{array}{c}5895.74 \pm \\
2427.25\end{array}$ & $\begin{array}{c}16561.54 \pm \\
9192.08\end{array}$ & $\begin{aligned} t & =28.61 p \\
& <0.001\end{aligned}$ \\
\hline \multirow{4}{*}{$\begin{array}{l}\text { Physical } \\
\text { component } \\
\text { summary }\end{array}$} & Much below average & $31(23.8)$ & $43(33.1)$ & $74(28.5)$ & \multirow{4}{*}{$\begin{array}{c}x^{2}=9.12 \\
d f=3 \\
p<0.05\end{array}$} \\
\hline & Below average & $19(14.6)$ & $23(17.7)$ & $42(16.2)$ & \\
\hline & Average & $74(56.9)$ & 64 (49.2) & $138(53.1)$ & \\
\hline & High average & $6(4.6)$ & $0(0.0)$ & $6(2.3)$ & \\
\hline \multirow{4}{*}{$\begin{array}{l}\text { Mental } \\
\text { components } \\
\text { summary }\end{array}$} & Much below average & $26(20.0)$ & $53(40.8)$ & $79(30.4)$ & \multirow{4}{*}{$\begin{array}{c}x^{2}=19.13 \\
d f=3 \\
p<0.001\end{array}$} \\
\hline & Below average & $34(26.2)$ & $14(10.8)$ & $48(18.5)$ & \\
\hline & Average & $70(53.8)$ & $62(47.7)$ & $132(50.8)$ & \\
\hline & High average & $0(0.0)$ & $1(0.8)$ & $1(0.4)$ & \\
\hline
\end{tabular}

- $\quad$ Percentage in parenthesis 
Table-II: Correlation between socio-demographic characteristics with PCS and MCS of HRQoL of urban and rural elderly

\begin{tabular}{|c|c|c|c|c|c|c|}
\hline \multirow{2}{*}{ Independent variable } & \multirow{2}{*}{$\begin{array}{c}\text { Components of } \\
\text { HRQoL }\end{array}$} & \multicolumn{2}{|c|}{ Urban $(n=130)$} & \multicolumn{2}{|c|}{ Rural $(n=130)$} & \multirow{2}{*}{ Test of correlation } \\
\hline & & $r$ value & $p$ value & $r$ value & $p$ value & \\
\hline \multirow{2}{*}{ Occupation } & PCS & $r=-.066$ & $p=.455$ & $r=.003$ & $p=.973$ & \multirow{8}{*}{ Spearman } \\
\hline & MCS & $r=-.167$ & $p=.058$ & $r=-.053$ & $p=.550$ & \\
\hline \multirow{2}{*}{ Education Level } & PCS & $r=.300$ & $\mathrm{p}=.001$ & $r=.339$ & $p=.000$ & \\
\hline & MCS & $r=407$ & $p=.000$ & $r=.250$ & $p=.004$ & \\
\hline \multirow{2}{*}{ Marital status } & PCS & $r=-.420$ & $p=.000$ & $r=-.325$ & $p=.000$ & \\
\hline & MCS & $r=-.359$ & $p=.000$ & $r=-.233$ & $p=.008$ & \\
\hline \multirow{2}{*}{ Family type } & PCS & $r=-.183$ & $\mathrm{P}=.037$ & $r=-.154$ & $\mathrm{P}=.079$ & \\
\hline & MCS & $r=-.035$ & $\mathrm{P}=.690$ & $r=-.176$ & $\mathrm{P}=.045$ & \\
\hline \multirow{2}{*}{$\begin{array}{l}\text { Monthly family } \\
\text { income }\end{array}$} & PCS & $r=.016$ & $\mathrm{P}=.861$ & $r=.058$ & $\mathrm{P}=.511$ & \multirow{2}{*}{ Pearson } \\
\hline & MCS & $r=.070$ & $P=.429$ & $r=.142$ & $P=.107$ & \\
\hline
\end{tabular}

Table-III: Comparison of physical component summary and mental component summary score of urban and rural elderly

\begin{tabular}{|l|c|c|c|}
\hline Component of HRQoL & Elderly & Mean \pm SD & Test of significance \\
\hline \multirow{2}{*}{ Physical component summary } & Urban & $45.68 \pm 6.366$ & \multirow{t}{*}{$\mathrm{t}=4.082$} \\
& Rural & $42.43 \pm 6.467$ & $\mathrm{p}=.000$ \\
\hline \multirow{2}{*}{ Mental component summary } & Urban & $43.96 \pm 4.921$ & $\mathrm{t}=1.865$ \\
\cline { 2 - 3 } & Rural & $42.56 \pm 7.028$ & $\mathrm{p}=.063$ \\
\hline
\end{tabular}

\section{Discussion}

In this study, among the all respondents, the majority i.e. 140 (53.8\%) were belong to the age group 60-69 years. The mean age of the elderly was $69.26 \pm 6.337$ years with a range of $60-85$ years. The mean monthly household income of the respondents was Taka 16561.54 \pm 9192.076 . As per report by Bangladesh Bureau of statistic, mean monthly household income is $15,945.00 \mathrm{BDT}$. This was found almost similar to respondents' monthly household income in this study. Most of the elderly respondents i.e. 240(92.31\%) were from joint family. A similar study was conducted on 280 elderly respondents in a rural area of Bangladesh where $131(46.8 \%)$ were living in joint family5. This study differed from that study may be due to change of study place.

In this study, around half of the respondents i.e. 138 (53.1\%) and 132 (50.8\%) had "Average" level of PCS and MCS respectively. The mean score of PCS was $44.05 \pm 6.608$ with a range of 28 to 60 and MCS was $43.26 \pm 6.096$ with a range of 30 to 56 . A similar study in Taiwan on elderly people revealed that the mean score of PCS and MCS using SF 36 v 2 surveys were $44.73 \pm 10.61$ and $56.12 \pm 9.32$ respectively 6 . Present study was found inconsistent with that study. Among the respondents, rural male respondents also had higher mean PCS score and MCS score than those of female respondents with statistical significance $(t=2.378, p<0.05)$. A population-based conducted in Brazil to find HRQOL using SF 36 survey revealed worse physical and mental domain of HRQoL?. These findings reflect the vulnerable health situation of females in developing and middle-income countries amidst progressive women empowerment.

Among all elderly, high PCS and MCS scores were found in respondents with high educational level i.e. "bachelor's degree and above". In urban respondents, these scores were $46.67 \pm 6.472$ and $46.06 \pm 4.238$; in rural respondents these scores were $47.11 \pm 1.556$ and 49.50 \pm 3.224 . A similar study was conducted in Spain to see the association between education and HRQoL in elderly citizen. That study revealed lower educational level is associated with unhappiness, poor social relationship, poor self-assessment and health problem in elderly8. Among urban and rural respondents, highest mean scores of PCS and MCS were found in married elderly which were $47.50 \pm 5.556$ and $45.08 \pm 4.502$ and in rural score were $44.74 \pm 5.539$ and $44.51 \pm 6.549$ respectively. A study conducted in Brazil, revealed married individuals obtained higher scores than widow/widower, even after adjusting the age and gender ${ }^{9}$.

Among the respondents, mean score of PCS of urban and rural respondents were $45.68 \pm 6.366$ and $42.43 \pm 6.467$ respectively. This difference was statistically significant ( $t$ test $=4.082, p<.001)$. The mean scores of MCS of urban and rural respondents were $43.96 \pm 4.921$ and $42.56 \pm 7.028$ respectively. This difference was not statistically significant (t test $=1.865, p>05$ ). So, this study, physical aspects of HRQoL was found significantly higher in urban elderly than rural.

\section{Conclusion}

This comparative cross-sectional study was conducted among urban and rural elderly to assess and compare their HRQoL. In this study, more than half of the all elderly had average level of PCS and MCS of HRQoL. Female elderly had low mean PCS and MCS score than male among all elderly, but the difference was found statistically significant for PCS in rural elderly. Both urban and rural elderly with higher education levels and married had higher mean score of PCS and MCS. Occupation and monthly family income had association with PCS and MCS with no statistical significance. Unemployed and low monthly income elderly had low mean PCS and MCS score in both urban and rural elderly. Urban elderly had higher mean PCS and MCS score than that of rural, but difference was statistically significant for PCS only. As HRQoL was found lower among rural elderly, particularly in female elderly, so a countrywide comprehensive and sustainable measure should be taken for better health and wellbeing of rural elderly. 


\section{References}

1. Rahman M. Aging and Negligence in Bangladesh. Journal of Gerontology \& Geriatric Research 2017; 6(3):14-7.

2. Uddin M. Social Support of Older Persons in Bangladesh. Journal of Public Policy and Administration 2017; 5(1):44-6.

3. CDC. Health Related Quality of life. Available at https://uww. cdc.gov/hrqol/concept.htm [Accessed on 20 Apr 2015].

4. Bangladesh Bureau of Statistic. Population census 2011: National report (Provisional). Dhaka: Ministry of Planning, Bangladesh 2016; 12(4):36-40.

5. Uddin $M$, Soivong $P$, Lasuka $D$ et al. Factors related to quality of life among older adults in Bangladesh: A cross sectional survey. Nursing Health Science 2017; 19(4):518-24.
6. Chang H, Chen $\mathrm{C}$ and Liu L. Health-Related Quality of Life of Senior Veterans Living in Veterans Homes. Taiwanese Gerontological Forum 2010; 7(2):24-5.

7. Lima M, Barros B and César C. (2015). Health related quality of life among the elderly: a population-based study using SF-36 survey. Cad Saude Publication 2015; 25(10):215-67.

8. Lasheras $C$, Patterson A, Casado $C$ et al. Effects of education on the quality of life, diet and cardiovascular risk factors in an elderly Spanish community population. Journal of Experimental Aging Research 2001; 27(3):10-2.

9. Wyss $K$, Wagner A, Whiting $D$ et al. Validation of the Kiswahili version of the SF-36 Health Survey in a representative sample of an urban population in Tanzania. Quality Life Res 2016; 8(1):111-20. 